\title{
Fluconazole in the treatment of Cushing's disease
}

\author{
Kharis Burns $^{1,2}$, Darshika Christie-David ${ }^{2,3}$ and Jenny E Gunton ${ }^{1,2,4,5,6}$ \\ ${ }^{1}$ Department of Diabetes and Endocrinology, Westmead Hospital, Sydney 2145, Australia \\ ${ }^{2}$ Faculty of Medicine, Westmead Hospital, University of Sydney, Sydney 2145, Australia \\ ${ }^{3}$ Department of Endocrinology, Royal North Shore Hospital, St Leonards 2065, Australia \\ ${ }^{4}$ St Vincent's Clinical School, University of New South Wales, Sydney 2010, Australia \\ ${ }^{5}$ Diabetes and Transcription Factors Group, Garvan Institute of Medical Research (GIMR), Sydney 2010, Australia \\ ${ }^{6}$ Department of Diabetes, Obesity and Endocrinology, The Westmead Institute for Medical Research, The University \\ of Sydney, Sydney 2145, Australia
}

\author{
Correspondence \\ should be addressed \\ to K Burns \\ Email \\ kbur9770@uni.sydney.edu.au
}

\section{Summary}

Ketoconazole was a first-line agent for suppressing steroidogenesis in Cushing's disease. It now has limited availability. Fluconazole, another azole antifungal, is an alternative, although its in vivo efficacy is unclear. A 61-year-old female presented with weight gain, abdominal striae and worsening depression. HbA1c increased to $76 \mathrm{mmol} / \mathrm{mol}$ despite increasing insulin. Investigations confirmed cortisol excess; afternoon serum cortisol was $552 \mathrm{nmol} / \mathrm{l}$ with an inappropriate ACTH of $9.3 \mathrm{pmol} / \mathrm{l}$. In total, 24-h urinary free cortisol (UFC):creatinine ratio was $150 \mathrm{nmol} / \mathrm{mmol}$ with failure to suppress after $48 \mathrm{~h}$ of low-dose dexamethasone. Pituitary MRI revealed a 4-mm microadenoma. Inferior petrosal sinus sampling confirmed Cushing's disease. Transsphenoidal resection was performed and symptoms improved. However, disease recurred 6 months later with elevated $24-\mathrm{h}$ UFC $>2200 \mathrm{nmol} /$ day. Metyrapone was commenced at $750 \mathrm{mg}$ tds. Ketoconazole was later added at $400 \mathrm{mg}$ daily, with dose reduction in metyrapone. When ketoconazole became unavailable, fluconazole $200 \mathrm{mg}$ daily was substituted. Urine cortisol:creatinine ratio rose, and the dose was increased to $400 \mathrm{mg}$ daily with normalisation of urine hormone levels. Serum cortisol and urine cortisol:creatinine ratios remain normal on this regimen at 6 months. In conclusion, to our knowledge, this is the first case demonstrating prolonged in vivo efficacy of fluconazole in combination with low-dose metyrapone for the treatment of Cushing's disease. Fluconazole has a more favourable toxicity profile, and we suggest that it is a potential alternative for medical management of Cushing's disease.

\section{Learning points:}

- Surgery remains first line for the management of Cushing's disease with pharmacotherapy used where surgery is unsuccessful or there is persistence of cortisol excess.

- Ketoconazole has previously been used to treat cortisol excess through inhibition of CYP450 enzymes $11-\beta$-hydroxylase and 17- $\alpha$-hydroxylase, though its availability is limited in many countries.

- Fluconazole shares similar properties to ketoconazole, although it has less associated toxicity.

- Fluconazole represents a suitable alternative for the medical management of Cushing's disease and proved an effective addition to metyrapone in the management of this case.

\section{Background}

The management of pituitary adrenocorticotrophin (ACTH) Cushing's disease involves surgery as the firstline intervention. Medical therapy may be introduced to control cortisol excess in circumstances where disease is not definitively cured via resection or there is a surgical contraindication (1) (2).

Ketoconazole was a first-line agent for suppressing adrenal steroid production in Cushing's disease, although it is now widely unavailable. Furthermore most medical 
therapies available to treat Cushing's Disease are associated with toxicity. Fluconazole, another azole antifungal, represents an alternative treatment option with a favourable adverse effect profile, although its in vivo efficacy has previously been unclear. This case demonstrates the novel and successful use of fluconazole in the management of Cushing's disease. Currently, with limited availability of ketoconazole and significant toxicities associated with other pharmacotherapies, fluconazole has been a suitable alternative.

\section{Case presentation}

A 61-year-old Indian female presented with weight gain, facial swelling, abdominal striae and worsening depression on a background of type 2 diabetes mellitus (T2DM), hypothyroidism, hypercholesterolemia, hypertension and ischemic heart disease. She had chronic shoulder pain, fibromyalgia and osteoporosis (lumbar spine T score -2.5 ) with no past fractures.

T2DM was managed with insulin aspart tds, insulin glargine nocte, metformin $1 \mathrm{~g}$ tds and gliclazide MR $120 \mathrm{mg}$. There was no history of corticosteroid use. Family history was significant for T2DM and ischaemic heart disease in her father. There was no family history of endocrine tumours. The patient was married with two children, was a non-smoker and drank no alcohol.
History additionally revealed $10 \mathrm{~kg}$ of weight gain over two years, blurred vision, easy bruising, fatigue and irritability. Her HbA1c deteriorated to $76 \mathrm{mmol} / \mathrm{mol}$, from $66 \mathrm{mmol} / \mathrm{mol}, 18$ months earlier, despite increasing insulin doses. Home blood glucose levels (BGL) revealed BGLs 306-407 mg/dl (17-22.6 mmol/l).

On examination, the patient had prominent supraclavicular and dorsocervical fat pads, moon facies, abdominal obesity and striae, proximal muscle weakness but no acanthosis nigricans. Her weight was $78.3 \mathrm{~kg}$, height $157 \mathrm{~cm}$ and BMI $31.8 \mathrm{~kg} / \mathrm{m}^{2}$. Blood pressure was $148 / 85 \mathrm{mmHg}$ and heart rate $80 \mathrm{bpm}$ while on 4 antihypertensive medications. There was mild, long-standing pedal oedema.

\section{Investigation}

Initial investigations are shown in Table 1 . An afternoon serum cortisol was $599 \mathrm{nmol} / \mathrm{l}$. In total, 24-h urinary free cortisol (UFC) was $757 \mathrm{nmol} /$ day. In all, 24-h UFC/creatinine ratio was elevated at $150 \mathrm{nmol} / \mathrm{mmol}$ (normal range 25-70). Cortisol failed to suppress during a 48-h low-dose dexamethasone suppression test (nadir $452 \mathrm{nmol} / \mathrm{l}$, with ACTH 11.1 pmol/l). Similarly, no suppression was seen with high-dose dexamethasone. A pituitary MRI demonstrated a 4-mm left inferior microadenoma. Inferior petrosal sinus (IPS) sampling with corticotrophin-releasing

Table 1 Investigation results.

\begin{tabular}{|c|c|}
\hline Test & Result \\
\hline 24-h UFC & $757 \mathrm{nmol} / \mathrm{day}$ \\
\hline 24-h UFC:creatinine ratio & $150.4 \mathrm{nmol} / \mathrm{mmol} \mathrm{Cr}$ \\
\hline Late afternoon cortisol & $599 \mathrm{nmol} / \mathrm{l}$ \\
\hline Afternoon cortisol & $552 \mathrm{nmol} / \mathrm{l}$ \\
\hline Paired afternoon ACTH & $9.3 \mathrm{pmol} / \mathrm{l}$ \\
\hline \multicolumn{2}{|c|}{ 48-h 2-mg low-dose dexamethasone suppression test ( $0.5 \mathrm{mg}$ q6h) } \\
\hline Nadir cortisol & $452 \mathrm{nmol} / \mathrm{l}$ \\
\hline \multicolumn{2}{|c|}{ 48-h 8-mg high-dose dexamethasone suppression test ( $2 \mathrm{mg} \mathrm{q} 6 \mathrm{~h}$ ) } \\
\hline Nadir cortisol & $450 \mathrm{nmol} / \mathrm{l}$ \\
\hline$\%$ Change from baseline & $18.5 \%$ suppression \\
\hline \multicolumn{2}{|l|}{ CRH Stimulation } \\
\hline Baseline ACTH & $1.6 \mathrm{pmol} / \mathrm{l}$ \\
\hline Peak ACTH & $12.6 \mathrm{pmol} / \mathrm{l}$ \\
\hline Baseline cortisol & $197 \mathrm{nmol} / \mathrm{l}$ \\
\hline Peak cortisol & $452 \mathrm{nmol} / \mathrm{l}$ \\
\hline \multicolumn{2}{|l|}{ IPS sampling } \\
\hline Left IPS: peripheral ACTH ratio & 12.3 \\
\hline Right IPS: peripheral ACTH ratio & 8.8 \\
\hline Post-CRH left IPS: peripheral ACTH ratio & 48.2 \\
\hline Post-CRH right IPS: peripheral ACTH ratio & 13.7 \\
\hline Left IPS: peripheral prolactin ratio & 1.9 \\
\hline Right IPS: peripheral prolactin ratio & 2.5 \\
\hline Left: right prolactin-adjusted ACTH ratio & 5.1 \\
\hline
\end{tabular}

Reference range

300-900 nmol/day

$25-70 \mathrm{nmol} / \mathrm{mmol} \mathrm{Cr}$

$80-480 \mathrm{nmol} / \mathrm{l}$

$80-480 \mathrm{nmol} / \mathrm{l}$

$0-12 \mathrm{pmol} / \mathrm{l}$

Expect cortisol suppressed $<50 \mathrm{nmol} / \mathrm{l}$ at $48 \mathrm{~h}$

Expect $>50 \%$ suppression for a positive test for Cushing's disease

Expect $>50 \%$ increase in Cushing's disease

Expect $>20 \%$ increase in Cushing's disease

Expect $>2.0$ in Cushing's disease

Expect $>3.0$ in Cushing's disease

Expect $\geq 1.8$ in successful catheterisation

$\geq 1.4$ suggests lateralisation 
hormone (CRH) stimulation confirmed a pituitary source of ACTH secretion and lateralised to the left with a ratio of 5.1 ( $>1.4$ suggests lateralisation).

Transsphenoidal neurosurgery was performed. Histopathology showed only normal pituitary tissue. The patient was managed with hydrocortisone postoperatively with a weaning dose. Following withdrawal of hydrocortisone, the serum cortisol was $348 \mathrm{nmol} / \mathrm{l}$, with ACTH $5.8 \mathrm{pmol} / \mathrm{l}$. Over the next 2 months, she lost a small amount of weight, glycaemic control improved and her blood pressure normalised.

Approximately 6 months after the surgery, the patient again complained of weight gain, hypertension, hyperglycaemia and facial swelling. Home blood pressure recordings showed systolic readings $>200 \mathrm{mmHg}$. Serum cortisol was $944 \mathrm{nmol} / 1$ with paired ACTH $22.0 \mathrm{pmol} / 1$ and repeat urine samples confirmed elevated cortisol: creatinine ratios.

Repeat MRI showed a 4-mm hypointense lesion in the floor of the pituitary fossa consistent with the original microadenoma.

\section{Treatment}

The patient was commenced on metyrapone $750 \mathrm{mg}$ tds. She became clinically Addisonian with hypotension (BP 96/50 mmHg), postural dizziness, nausea and weight loss a few weeks after the commencement of therapy. A block and replace regimen was commenced, and hydrocortisone, at doses of $20 \mathrm{mg}$ mane and $10 \mathrm{mg}$ nocte, was added. The addition of hydrocortisone did not significantly affect the trend in biochemistry, although around 10 weeks after its commencement, the urine cortisol:creatinine ratio began to increase (Fig. 1). The hydrocortisone dose was later decreased to $15 \mathrm{mg}$ mane and $8 \mathrm{mg}$ nocte.

Definitive treatment options were discussed including repeat surgery, stereotactic radiotherapy and bilateral adrenalectomy. The patient declined repeat surgery and eventually opted for gamma-knife radiation treatment, though treatment was delayed for 6 months (Fig. 1).

Despite metyrapone, the urine cortisol levels remained elevated; spot urinary cortisol:creatinine ratio was $57.7 \mu \mathrm{mol} / \mathrm{mol}$ (normal <30); so, ketoconazole $400 \mathrm{mg}$ daily was added with good effect (Fig. 1). In all, 6 weeks later, the urine cortisol:creatinine ratio was normal $23.1 \mu \mathrm{mol} / \mathrm{mol}$ (ref <30). Metyrapone was decreased to $500 \mathrm{mg}$ bd, and the patient remained wellcontrolled for several months.

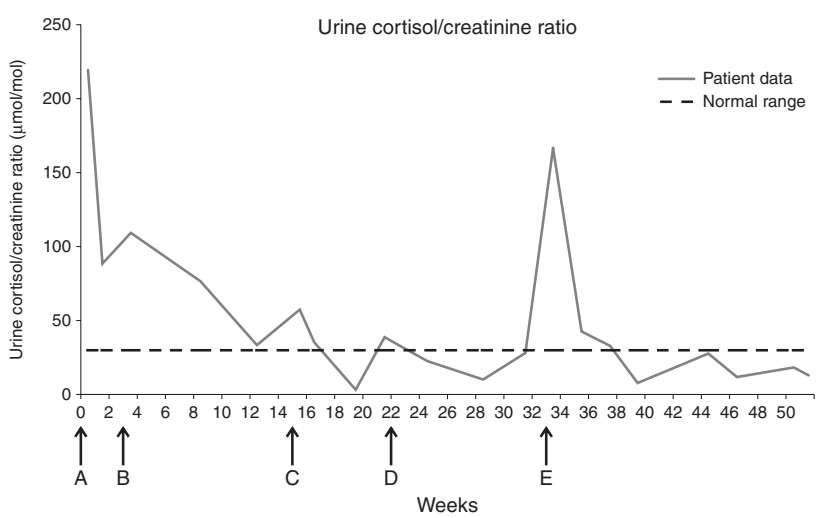

Figure 1

Trend of urine cortisol:creatinine ratio over time with the introduction of new therapies. A, metyrapone $750 \mathrm{mg}$ tds commenced; B, hydrocortisone $20 \mathrm{mg}$ mane/10 $\mathrm{mg}$ afternoon commenced 3 weeks later; $C$, ketoconazole $400 \mathrm{mg}$ daily started, metyrapone reduced to $500 \mathrm{mg}$ bd; D, fluconazole $200 \mathrm{mg}$ daily started; E, fluconazole dose increased to $400 \mathrm{mg}$ daily. Note: Radiotherapy commenced after the end of the period described above.

Then, ketoconazole became unavailable. After examination of the CYP450 activity of the various azoles, fluconazole was prescribed at $200 \mathrm{mg}$ daily. This was increased to $400 \mathrm{mg}$ daily, and her serum cortisol and urine cortisol:creatinine ratio normalised (Fig. 1).

\section{Outcome and follow-up}

In total, 6 months later, the patient remained stable on metyrapone and fluconazole, and her radiotherapy was administered. Following the commencement of radiotherapy, metyrapone was withdrawn and the patient remained stable on fluconazole alone at a dose of $400 \mathrm{mg}$ daily. To our knowledge, this is the first case demonstrating prolonged in vivo efficacy of fluconazole as a steroid inhibitor for the treatment of Cushing's disease.

\section{Discussion}

First-line management of Cushing's disease is surgery. Medical therapy is used where disease is not cured via resection (1). Transsphenoidal pituitary tumour resection is quoted to be successful in up to $75-80 \%$ of cases with the remaining $20-25 \%$ requiring adjuvant pharmacotherapy (1). Recurrence occurs in $\sim 20 \%$ of patients within 2-4 years (1).

\section{Medical treatment options}

In circumstances of persistent cortisol excess, or where surgery is contraindicated, pharmacotherapy may be 
necessary (1) (3) (4). A range of medical therapies are available. Most drugs inhibit adrenal synthesis of cortisol. Ketoconazole, an imidazole derivative, has been used for its ability to block CYP450 enzymes 11- $\beta$-hydroxylase and 17- $\alpha$-hydroxylase (1). At doses of 200-600 mg daily, it effectively inhibits adrenal and gonadal steroidogenesis. In cases of severe hypercortisolism, doses of up to $1200 \mathrm{mg}$ daily may be used (5). Its ability to maintain a reduction in UFC and to rapidly improve and control the features of Cushing's syndrome has been well described and led to its recommendation as a first-line agent for medical management (4) (6).

Despite efficacy, ketoconazole is not without adverse effects. Hepatotoxicity is recognised, though usually mild to moderate, and the risk of severe hepatic failure is low (5). Gastrointestinal side effects are common, gynaecomastia is reported and, except in Cushing's syndrome, its CYP450 inhibition is undesirable (4) (5) (6).

Fluconazole is another azole compound and a recognised alternative to ketoconazole in the treatment of fungal infections. This drug has fewer side effects; in particular, hepatotoxicity is less common (7). Fluconazole is unique in chemical structure and pharmacologic profile (8). Historically, these two agents have been used for the treatment of similar conditions; however, there has been little investigation into the use of fluconazole as a treatment for Cushing's syndrome to date. One case report indicates benefit in cortisol excess due to adrenal carcinoma (3), and its efficacy in ectopic ACTH production has also recently been recognised (9). There are no reports of its use in Cushing's disease. In contrast, several case reports discount any ability of this medication to suppress cortisol production (10) (11).

Nevertheless, case reports document incidental adrenal suppression as a side effect of fluconazole used for antifungal purposes. Further reports have documented adrenal insufficiency as a result of inhibition of fluconazole metabolism through interactions with medications utilising the same CYP450 pathway (12). This 'adverse effect' demonstrates its ability to inhibit steroidogenesis and suggests potential benefit in Cushing's syndrome.

In vitro studies have proven the ability of fluconazole to suppress human cortisol production in cultured adrenal cortical carcinoma and human adrenal cortical cells (13). Specifically, the ability of fluconazole to block the activity of 11- $\beta$-hydroxylase and 17- $\alpha$-hydroxylase enzymes has been confirmed (13). One study comparing the in vitro potency of ketoconazole and fluconazole found higher potency with the former, though confirmed a reduction in cortisol with fluconazole use (13).

\section{Fluconazole and CYP450 interaction}

The ability of ketoconazole to suppress steroidogenesis has been attributed to binding and subsequent impairment of CYP450 enzyme action. Pharmacokinetic studies have shown that fluconazole similarly inhibits CYP450 enzymes; however, ketoconazole is at least three-fold more potent (14). Ketoconazole is extensively hepatically metabolised, potentially contributing to increased hepatotoxicity (8). In contrast, fluconazole is minimally metabolised, with $80 \%$ excreted unchanged in the urine (8).

This case shows that fluconazole may be a suitable alternative to ketoconazole in the medical management of Cushing's disease. Despite conflicting reports in the literature, we report successful suppression of urine cortisol:creatinine ratio in a patient with Cushing's disease, over 6 months of treatment with fluconazole. While it is recognised that variability in urine cortisol excretion exists in patients with Cushing's disease, the rise in cortisol following ketoconazole cessation and subsequent biochemical improvement with the introduction of fluconazole supports efficacy of fluconazole in controlling cortisol excess. Given a more favourable toxicity profile and issues with ketoconazole access, we suggest that fluconazole is a possible alternative in the medical management of Cushing's disease where surgery is unsuccessful, declined by the patient or contraindicated.

Declaration of interest

The authors declare that there is no conflict of interest that could be perceived as prejudicing the impartiality of the research reported.

\section{Funding}

This research did not receive any specific grant from any funding agency in the public, commercial or not-for-profit sector.

\section{Patient consent}

Written informed consent has been obtained from the patient, and a signed copy of the consent form is provided.

Author contribution statement

All three authors, Dr K Burns, Dr D Christie-David and Professor J E Gunton contributed to the preparation of this manuscript.

\section{References}

1 Schteingart DE 2009 Drugs in the medical treatment of Cushing's syndrome. Expert Opinion on Emerging Drugs 14 661-671. (doi:10.1517/ 14728210903413522) 
2 Castinetti F, Morange I, Jaquet J, Conte-Devolx B \& Brue T 2008 Ketoconazole revisited: a preoperative or postoperative treatment in Cushing's disease. European Journal of Endocrinology/European Federation of Endocrine Societies 158 91-99. (doi:10.1530/EJE-07-0514)

3 Riedl M, Maier C, Zettinig G, Nowotny P, Schima W \& Luger A 2006 Long term control of hypercortisolism with fluconazole: case report and in vitro studies. European Journal of Endocrinology/European Federation of Endocrine Societies 154 519-524. (doi:10.1530/eje.1.02120)

4 Nieman LK 2002 Medical therapy of Cushing's disease. Pituitary 5 77-82. (doi:10.1023/A:1022308429992)

5 Castinetti F, Guignat L, Giraud P, Muller M, Kamenicky P, Drui D, Caron P, Luca F, Donadille B, Vantyghem MC et al. 2014 Ketoconazole in Cushing's disease: is it worth a try? Journal of Clinical Endocrinology and Metabolism 99 1623-1630. (doi:10.1210/jc.2013-3628)

6 Sonino N, Boscaro M, Paoletta A, Mantero F \& Ziliotto D 1991 Ketoconazole treatment in Cushing's syndrome: experience in 34 patients. Clinical Endocrinology 35 347-352. (doi:10.1111/ j.1365-2265.1991.tb03547.x)

7 Garcia Rodriguez LA, Duque A, Castellsague J, Perez-Gutthann S \& Stricker BH 1999 A cohort study on the risk of acute liver injury among users of ketoconazole and other antifungal drugs. British Journal of Clinical Pharmacology 48 847-852. (doi:10.1046/j.1365-2125.1999. 00095.x)

8 Como JA \& Dismukes WE 1994 Oral azole drugs as systemic antifungal therapy. New England Journal of Medicine 330 263-272. (doi:10.1056/ NEJM199401273300407)
9 Schwetz V, Aberer F, Stiegler C, Pieber TR, Obermayer-Pietsch B \& Pilz S 2015 Fluconazole and acetazolamide in the treatment of ectopic Cushing's syndrome with severe metabolic alkalosis. Endocrinology, Diabetes \& Metabolism Case Reports 2015 Article ID: 150027. (doi:10.1530/EDM-15-0027)

10 Magill SS, Puthanakit T, Swoboda SM, Carson KA, Salvatori R, Lipsett PA \& Hendrix CW 2004 Impact of fluconazole prophylaxis on cortisol levels in critically ill surgical patients. Antimicrobial Agents and Chemotherapy 48 2471-2476. (doi:10.1128/AAC.48.7.2471-2476. 2004)

11 Michaelis G, Zeiler D, Biscoping J, Fussle R \& Hempelmann G 1993 Function of the adrenal cortex during therapy with fluconazole in intensive care patients. Mycoses 36 117-123. (doi:10.1111/j.1439-0507. 1993.tb00698.x)

12 Johnson SR, Marion AA, Vrchotickey T, Emmanuel P \& LujanZilbermann J 2006 Cushing syndrome with secondary adrebal insufficiency from concomitant therapy with ritonavir and fluticasone. Journal of Pediatrics 148 386-388. (doi:10.1016/j.jpeds.2005.11.034)

13 van der Pas R, Hofland LJ, Hofland J, Taylor AE, Arlt W, Steenbergen J, van Koetsveld PM, de Herder WW, de Jong FH \& Feelders RA 2012 Fluconazole inhibits human adrenocortical steroidogenesis in vitro. Journal of Endocrinology 215 403-412. (doi:10.1530/JOE-12-0310)

14 Ervine C, Matthew D, Brennan B \& Houston J 1996 Comparison of ketoconazole and fluconazole as cytochrome P450 inhibitors. Use of steady-state infusion approach to achieve plasma concentrationresponse relationships. Drug Metabolism and Disposition: the Biological Fate of Chemicals 24 211-215.

Received in final form 14 January 2016

Accepted 20 January 2016 